Bartın Üniversitesi

Eğitim Fakültesi Dergisi

Cilt 5, Sayı 3, s. 908-923, Ekim 2016

BARTIN - TÜRKIYE

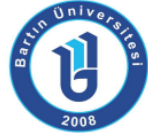

ISSN: 1308-7177
Bartin University

Journal of Faculty of Education

Volume 5, Issue 3, p. 908-923, October 2016

BARTIN - TURKEY

\title{
Fen Öğretiminde Karma Öğrenme: Öz-yeterlik İnancı ve Teknolojiye Yönelik Tutuma Etkisi
}

Bekir GÜLER, Arş. Gör., Bartın Üniversitesi Eğitim Fakültesi, bguler@bartin.edu.tr

Mehmet ŞAHIN, Prof. Dr., Dokuz Eylül Üniversitesi Eğitim Fakültesi, mehmet.sahin@deu.edu.tr

Öz: Bu çalışmanın amacı, karma öğrenme yönteminin fen bilgisi öğretmen adaylarının fen öğretimine yönelik öz-yeterlik inançlarına ve teknolojiye yönelik tutumlarına etkisini araştırmaktır. Çalışma, 2014-2015 öğretim yılı güz döneminde 88 Fen Bilgisi öğretmen adayı ile gerçekleştirilmiştir. Bir dönem boyunca devam eden çalışmada dersler, deney grubunda karma öğrenme yöntemi ile yürütülürken, kontrol grubunda geleneksel yüz yüze eğitim ile yürütülmüştür. Veri toplama araçları olarak "Fen Öğretiminde Öz-yeterlik İnancı Ölçeği” ve "Teknolojiye Yönelik Tutum Ölçeği” kullanılmıştır. Bunlara ek olarak, deney grubundan seçilen katılımcılarla yarı yapılandırılmış görüşme yapılarak nitel veriler toplanmıştır. Elde edilen nicel bulgular, her iki grubun da fen öğretimine yönelik öz-yeterlik inancı puanlarında düşüş olduğunu gösterirken, deney grubunda bu düşüşün daha fazla olduğu görülmüştür. Buna ek olarak deney grubunun teknolojiye yönelik tutum puanlarında düşüş olurken, kontrol grubunun puanlarında artış olduğu görülmüştür. Nitel verilerden elde edilen bulgular, bu olumsuz etkinin sebeplerini, bu çalışmada karma öğrenme ortamının bileşeni olarak kullanılan Moodle öğrenme yönetim sistemi ve katılımcıların lisans eğitimleri olarak açıklamıştır.

Anahtar Kelimeler: karma öğrenme, fen öğretimine yönelik öz-yeterlik inancı, teknolojiye yönelik tutum.

\section{Blended Learning in Science Teaching: Effects on Self- efficacy Belief and Attitude towards Technology}

\begin{abstract}
The purpose of this study was to investigate the effects of blended learning method on preservice science teachers' self-efficacy beliefs towards science teaching and attitudes towards technology. The study was carried out with 88 preservice science teachers in fall semester of the academic year 2014-2015. In this one semester length study, courses in experimental group were conducted using blended learning method while traditional face to face method was used in the control group. As data collection tools, "Self-efficacy Beliefs Instrument in Science Teaching" and "Scale for Attitudes Towards Technology" were used. In addition, qualitative data was collected via semistructured interviews with participants from the experimental group. The quantitative findings showed that experimental group had lower scores while both groups' scores decreased in self-efficacy beliefs towards science teaching. In addition, control group's scores of attitudes towards technology increased while the experimental group's score decreased. Qualitative findings explained the reasons for this negative effect with Moodle learning management system which was used as a component of blended learning environment in the study and participants' undergraduate education.
\end{abstract} technology.

Key Words: blended learning, self-efficacy belief towards science teaching, attitude towards 


\section{GíRiş}

Bireylerin gerek eğitim ortamlarına katılamama gerekse katıldıkları eğitim ortamlarında bir takım materyallere ya da içeriklere ulaşamama durumlarının çözülebilmesi için teknolojinin işe koşulduğu yeni yöntemler ortaya konulmuştur. Bunlardan birisi de "Karma Öğrenme" dir. Bu kavram, bilgisayarın öğrenme ortamlarında kullanıldığı Bilgisayar Destekli Öğrenme, buna ek olarak internetin de kullanıldığı İnternet Destekli Öğrenme ve Uzaktan Eğitim kavramlarının sonrasında ortaya çıkmıştır.

Bilgisayar ve internet destekli öğrenme ortamlarında öğrencilerin bu teknolojileri sadece okul içerisindeki belirli zamanlarda değil sürekli olarak kullanmalarını sağlamak amacıyla öğretim içeriğinin büyük bölümü internet ortamlarına ve bağlantılı yazılımlara aktarılmaya başlamıştır. Ve bu sayede yüz yüze eğitim ortamlarına ulaşmakta sıkıntı yaşayan bireylerin de sorunlarının çözülmesi hedeflenmiştir. Ancak bilgisayar, internet gibi teknolojilere veya bu teknolojilerin gerektirdiği alt yapılara sahip olamayan bireylerin bu öğrenmeden mahrum kalması gibi yeni bir sorun ortaya çıkmıştır. Dolayısıyla bireylerin daha önce sıkıntı yaşayan kısmının öğretim sürecine katılması sağlanırken, farklı bir kısmının da yeni sorunlarla karşılaşması söz konusu olmuştur. Bu durumu da göz önüne alan araştırmacılar "Karma Öğrenme" kavramını ortaya koymuşlardır. Karma Öğrenme, internet destekli öğretimin ve geleneksel olarak adlandırdığımız yüz yüze eğitimin birlikte uygulandığı süreçtir. Yani öğretim hem sınıf içerisinde yapılan etkinliklerle hem de sınıf dışında yapılan etkinliklerle sürdürülmektedir. Her ikisinde de teknolojiden faydalanılmakta olup, özellikle sınıf dışı etkinliklerde bilgisayar ve internet sayesinde sınıf içerisindeki gibi iletişim ve paylaşım ortamının sağlanması hedeflenmektedir. Dolayısıyla bireylerin hem sınıfta hem de sınıf dışında dersleri takip etmeleri ve öğrenmeyi sürekli hale getirmeleri mümkün olabilmektedir.

Yukarıda belirtilenler, karma öğrenmenin materyaller açısından gerekliliğini açıklamaktadır. Öğretim ortamlarındaki çevresel koşulların getirdiği gereklilikler dışında, karma öğrenmenin ortaya çıkmasının ve yayılmasının gerekliliğine işaret eden çeşitli araştırma sonuçları da bulunmaktadır. Cuban (1993)'ten aktaran Relan ve Gillani (1997), yüz yüze öğrenme ortamlarında öğretmenin merkezde olması sebebiyle öğrencilerin söylediklerinin daha geri planda kaldığını ve öğrencilerin bireysel farklııklarının göz ardı edildiğini belirtmişlerdir. Chang (2006), öğretmen merkezli yürütülen derslerin öğretmeni tek doğru olarak göstermesi sebebiyle öğrencilerin sorgulamalarını engellediğini ve yüzeysel öğrenmelerine sebep olduğunu belirtmiştir. Öğretmene olan bu bağılığı ortadan kaldırmak için öğretimin belirli bir zaman ve mekân ile sınırlandırılmasını önlemede teknolojinin faydalı olacağı belirtilmiştir (Turney, Robinson, Lee ve Soutar, 2009). Özellikle sınıf ortamına erişmede sorun yaşayan bireyler için başlatılan internet tabanlı ve uzaktan eğitimin, erişim sorununu çözmesinin yanında sınıfta kazanılan birtakım beceriler açısından olumsuz yanlarının olduğu belirtilmiştir. Dezavantaj olarak görülen özelliklerden en önemlisinin ise sınıf ortamında gerçekleşen öğrenci-öğretmen etkileşimini ortadan kaldırması olduğu belirtilmiştir (Caner, 2009; Panga, 2010).

Belirtilen durumlar neticesinde ortaya konulan karma öğrenmede, ders içeriklerinin büyük kısmı internet ortamı aracılığıyla sağlanırken, bu içerikleri destekleyici etkinlikler ve en önemlisi yüz yüze iletişim sınıf ortamında sağlanmaktadır. Öğrenciler etkinlikleri her iki ortamda da takip edebilmekte ve her iki ortamda da paylaşımda bulunabilmektedirler. Böylece yüz yüze eğitimin getirdiği kronolojik sıra ortadan kalkmakta, öğrenciler istedikleri zaman istedikleri yerde bilgiye ulaşabilmekte ve kendilerini geliştirebilmektedirler (Barrios ve diğer., 2014; Caner, 2009; Panga, 2010; Ünsal, 2007). 
Yapılan çalışmalarda karma öğrenme ortamlarında öğrencilerin daha rahat çalıştıkları ve bu çalışma ortamlarından memnun oldukları belirtilmiştir (Balcı, 2008; Karaman, Özen, Yıldırım ve Kaban, 2009). Ayrıca öğretmen adayları ile yapılan çalışmalarda öğretmen adaylarının öğretmenlik becerilerinin arttığı belirtilmiştir (Caner, 2009; İşman, Abanmy, Hussein ve Al Saadany, 2012). Akademik başarı, tutum gibi değişkenlerde ise yine karma öğrenme ile öğrenim gören öğrencilerin yüz yüze ve internet destekli eğitim gören öğrencilere göre anlamlı pozitif bir farka sahip oldukları belirtilmiştir (Aytaç ve Altunçekiç, 2012; Demirer, 2009; Rovai ve Jordan, 2004; Usta ve Mahiroğlu, 2008; Uzun ve Şentürk, 2010). Karma öğrenmenin yarattığı anlamlı farklılıkların yanı sıra, akademik başarı, teknolojiye yönelik tutum gibi değişkenler açısından anlamlı bir farkın bulunamadığı çalışmalar da vardır (Barkley, 2010; Güler, 2013; Lim ve diğer., 2014).

Öğretimsel teknoloji kullanımına olan ihtiyacın giderek arttı̆̆ı alanlardan birisi de fen eğitimidir. Fen eğitimi, karşılaştığı problemlere çözüm üreterek yaşam kalitesini artırabilecek bilinçli bireyler yetiştirmeyi hedeflemektedir. Dolayısıyla günlük hayatta yer alan tüm unsurlar fen eğitiminin içerisinde de kendisine bir yer bulmakta ve fen eğitiminin içeriğini meydana getirmektedir. Bu durum, fen öğretim sürecini kolaylaştırabilecek bileşenlere olan gereksinimi de beraberinde getirmektedir. Özellikle yeni öğretim programlarında öğrencilerin akademik başarıları tek hedef olmaktan çıkmıştır. Çünkü akademik başarının yanı sıra bireylerin duyuşsal durumlarının ve hem öğrenmelerini hem de yaşamlarını sürdürebilmeleri için gerekli olan birtakım becerilerinin geliştirilmesi de oldukça önem taşımaktadır. Bu kapsamda karma öğrenme yönteminin özellikle fen öğretim programının sık sık vurguladığı beceriler üzerinde nasıl bir etki yaptığının incelenmesi önemli olabilir. Karma öğrenme yönteminin beceriler üzerindeki etkilerini inceleyen çalışmalar nispeten az olmasına rağmen, yapılan çalışmalarda karma öğrenme yöntemi ile öğrenim gören öğrencilerin özdüzenleme ve bilimsel süreç becerileri üzerinde olumlu etkilerinin olduğu belirtilmiştir (Chou ve Chou, 2011; Güler, 2013). Ayrıca karma öğrenme (blended learning) ortamında öğrenim gören öğrencilerin hem fen öğretimine yönelik tutumlarında olumlu değişimler görülmüş, hem de öğrenme süreçlerini yönetebilme becerilerinin geliştiği belirtilmiştir (Akgündüz ve Akınoğlu, 2016). Benzer şekilde bu beceri ve tutum gelişimlerinin sağlanmasında öğretim sürecinin iyi planlanması ve kontrol edilmesi gerektiği de belirtilmiştir. Çünkü tüm öğretim yöntemlerinde olduğu gibi karma öğrenmede de etkili bir öğrenmenin sağlanabilmesi için öğretmenin rolü önemlidir. Öğretmenin bu süreçle ilgili tutum ve yeterliği, yürüteceği öğrenme sürecini de önemli ölçüde etkileyebilmektedir (Barrios ve diğer., 2014). Karma öğrenmenin uygulandığı öğrenme ortamında da öğretmenin teknolojiye yönelik tutum ve yeterlikleri, bu teknolojinin kullanılacağı öğrenme ortamını ve öğretim sürecini etkileyecektir. Öğretmenin tutumundan öğrencinin öğrenme isteğine ve öğrenme çıktılarına kadar uzanan bu süreç, fen öğretiminin etkililiğinin belirleyicisi olacaktır. Bu sebeple öğretmenlerin karma öğrenmenin öğrenme sürecindeki etkilerini derslerinde uygulamadan önce görmeleri ve deneyimlemeleri, öğrenme sürecinde etkili bir şekilde uygulamaları açısından önemlidir. Aynı zamanda karma öğrenmenin öğretmenler üzerindeki etkilerinin de bilinmesi, farklı seviyelerdeki uygulamaların bireyler üzerindeki etkilerinin karşılaştırılması açısından önemli olabilir.

Bu sebeple araştırmanın amacı, karma öğrenme yönteminin fen bilgisi öğretmen adaylarının fen öğretimine yönelik öz-yeterlik inançlarına ve teknolojiye yönelik tutumlarına etkisinin incelenmesidir. 


\section{YÖNTEM}

\subsection{Araştırma Modeli}

Araştırmada ön test-son test kontrol gruplu yarı deneysel desen kullanılmıştır. Yarı deneysel desende çalışılacak olan deney ve kontrol grupları yansız atama ile seçilir. Seçilen bu gruplara ön test ve son test uygulanır (Karasar, 2011). Araştırmada 2014-2015 güz yarıyılında 88 Fen Bilgisi öğretmen adayı ile çalışıımıştır. İki sınıftan oluşan bu grupların birisi deney (43), diğeri kontrol (45) grubu olarak belirlenmiştir. Uygulamalar için bir fen eğitimi dersi seçilmiş ve uygulama sürecinde dersler deney grubunda karma öğrenme yöntemi ile yürütülürken, kontrol grubunda geleneksel olarak da adlandırılmakta olan yüz yüze eğitim ile yürütülmüştür. Dersler için hazırlanan içeriklerin tamamı (ders föyleri, görsel materyaller, ara sınavlar, örnek deney raporları vb.) hem deney hem de kontrol grubunda kullanılmıştır. Öğretmen adaylarında meydana gelen değişim ve gelişimlerin belirlenmesinde, nicel ve nitel boyutların aynı çalışmada bir arada kullanıldığı karma yöntem tercih edilmiştir. Karma yöntem tasarımları arasından ise iç içe karma desen tercih edilmiştir. İç içe karma desende nitel ve nicel veriler aynı anda toplanır. Sonuçlar kısmında ise nicel ya da nitel verilerden birisine ağırlık verilerek diğer veriler destekleyici olarak kullanıı (Creswell, 2013). Araştırmada nicel verilere ağırlık verilerek, nitel verilerden nicel bulguların derinlemesine incelenebilmesi amacıyla faydalanılmıştır. Bu kapsamda nicel veri toplama araçları gruplara ön ve son test olarak uygulanmıştır. Ayrıca son testlerin ardından alınan puanlar doğrultusunda deney grubundan belirlenen 8 katılımcı ile yarı yapılandırılmış görüşme yapılmıştır.

\subsection{Veri Toplama Araçları}

Araştırmada öğretmen adaylarının teknolojiye yönelik tutumlarının belirlenmesinde Akbaba (2002) tarafından geliştirilmiş olan "Teknolojiye Yönelik Tutum Ölçeği” kullanılmıştır. Ölçek 37 maddeden oluşmakta olup beşli likert tipindedir. "Tamamen katılıyorum", "Katılıyorum", "Kararsızım", "Katılmıyorum" ve "Hiç katılmıyorum" cevap seçeneklerinden oluşan ölçeğin Cronbach Alpha güvenirlik katsayısı .64 olarak bulunmuştur. Katılımcıların fen öğretimine yönelik öz-yeterlik inançlarının belirlenmesinde ise Riggs ve Enochs (1990) tarafından geliştirilmiş ve Bıkmaz (2002) tarafından Türkçeye uyarlanmış olan "Fen Öğretiminde Öz-yeterlik İnancı Ölçeği" kullanılmıştır. Ölçek beşli likert tipinde olup 21 maddeden oluşmaktadır. Ölçekte yer alan maddelere verilen cevaplar "Kesinlikle katılıyorum", "Katılıyorum", "Kararsızım", "Katılmıyorum" ve "Kesinlikle katılmıyorum" şeklindedir. Ölçeğe ait Cronbach Alpha güvenirlik katsayısı .78 olarak bulunmuştur.

Nitel veriler ise, yarı yapılandırılmış görüşme yoluyla toplanmıştır. 4 soru ve bu sorulara verilen cevapları derinleştirebilmek amacıyla hazırlanan alt sorulardan oluşan görüşme formu 4 fen eğitimi uzmanı tarafından incelenmiştir. Uzmanlardan alınan dönütler doğrultusunda sorularda gerekli düzenlemeler yapılmıs olup, 5 öğretmen adayı ile gerçekleştirilen pilot çalışma sonrasında görüşme formuna çalışmada kullanılan son şekli verilmiştir.

\subsection{Uygulama Aşaması}

Çalışmada öncelikle karma öğrenmenin çevrimiçi uygulamalarının yürütülmesinde kullanılan Moodle öğrenme yönetim sisteminin çalışması ve olası eksikliklerin incelemesi yapılmıştır. Moodle, Martin Dougimas tarafından oluşturulan, açık kaynak kodlu, eğitimcilerin internet tabanlı bir ders ortamı ve verimli ders içerikleri oluşturmaları için geliştirilmiş bir öğrenme yönetim sistemidir (Altıparmak ve diğer., 2011; Elmas ve diğer., 2008; Sinecen, 2010). Açılımı Modular-Object-Oriented-Dynamic-Learning-Environment olan Moodle, bir ders içerisinde ihtiyaç duyulabilecek çalışmaların çoğunu yerine getirebilecek özelliklere sahip olup, hem öğretmen hem de öğrencileri açısından kullanımı kolay bir sistemdir (Altıparmak ve diğer., 
2011). Bu yüzden de piyasada yer alan diğer öğrenme yönetim sistemlerine (ATutor, Dokeos, Drupal, eFront vb.) oranla daha çok tercih edilen bir yazılımdır.

Uygulamaların yürütüleceği derse yönelik bir ders alanı oluşturularak Moodle sisteminde kullanıı kaydına aktif hale getirilmiştir. Ders ile ilgili paylaşımlar ilk ders itibariyle yapılacağı için başlangıçta sistemde sadece haftalık bölümler oluşturularak bu bölümlere ait Forum başlıkları hazırlanmıştır.

Grupların ilk ders gününde hem deney hem de kontrol grubuna ön testlerin uygulaması yapılmıştır. Derslerin ikinci bölümünde ise dönem boyunca dersin nasıl yürütüleceği hakkında bilgi verilmiştir. Buna göre:

- Sınıftaki öğrencilerin de istekleri dikkate alınarak 3 ve 4 kişilik gruplar oluşturulacak. Oluşturulan bu grupların listesi hazırlanarak her bir gruba dersin içeriğinde yer alan ve ilk derste sınıfa sunulacak olan konu listesinden bir konu verilecek.

- Oluşturulan bu grupların alacakları konular ile ilgili anlatım yapacakları bir hafta olacak. Belirtilen hafta bu grup konu hakkında yapmış olduğu araştırmalardan yola çıkarak sınıfta konu ile ilgili ve uygulamaları ile ilgili detaylı bilgi verecek.

- 2. Hafta grupların tamamı ve almış oldukları konular ilan edilmiş olacak.

- Konu anlatımından çok, araştırma sürecinde grupların sınıf ile paylaşım içerisinde olarak dönem boyunca konularını sınıfa öğretmeleri gerekecek. Bunu sunum öncesi ve sunum sonrası çalışmaları ile sağlayacaklar.

- Tüm bu çalışmalar sırasında deney grubuna Moodle sistemi üzerinden çalışma ortamı sunulacak. Bu sistemde, sınıftaki her öğrenci sisteme ilk dersin yapıldığı gün giriş yaparak üye olacak ders kaydı oluşturacak. Kayıt itibariyle sistemdeki tüm hareketlilikler ile ilgili e-posta almaya başlayacak. Sunumu yapacak olan gruba ait bir hafta oluşturulacak ve grup bu haftaya ait başlığın altındaki paylaşım klasörlerini ve forumları yönetecek. Konu anlatımından önceki haftalarda araştırmasının her safhası ile ilgili bilgi alışverişinde bulunurken, elde ettiği çeşitli görselleri ve sonuçları bu klasörler üzerinden sınıfla paylaşacak. Konu anlatımı için hazırladıkları Powerpoint gibi dosyaları önceden yükleyerek sınıfın haberdar olmasını sağlayacak. Ayrıca gerek konu anlatımı sırasında gerekse bunun dışında buldukları tüm materyal ve bilgileri yine kendilerine ait bölümde paylaşacaklar.

- Kontrol grubunda ise konulara ait araştırmalar ve paylaşımlar konusunda aynı çalışmalar yürütülecek. Ancak kontrol grubundaki tüm paylaşımlar grupların kendi belirleyecekleri yollarla (sosyal medya, CD ler, bellekler vs) yapılacak.

- Derslerde yapılacak tüm çalışmaların ardından her iki grupta da her ders sonunda grupların araştırma süreçleri, sunumları, sağladıkları kaynaklar ve süreç içerisinde sınıfla olan iletişim durumları ile ilgili tüm sınıf tarafından bir değerlendirme yapılacak.

- Her hafta sunumları yapacak olan gruplar konuları ile ilgili çoktan seçmeli sorular hazırlayarak sınıfla bu soruları da paylaşacak ve öğrenmeleri ile ilgili geri dönütler alacak.

- Gruplar, araştırmaları sürecinde daha düzenli ve doğru bir yol izleyebilmeleri için dersi yürüten araştırmacılardan destek alabilecekler. Teknik konularda ise yine araştırmacıların destekleriyle sisteme gerekli yüklemeleri yapacaklar.

Deney ve kontrol gruplarına gereken bu bilgiler verildikten sonra, grupların isimlerinin yer aldığı listeler oluşturularak gruplara ait konuların dağılımı ve anlatım haftaları belirlenmiştir. Deney grubunda gerçekleşen üyelik işlemlerinin hızlı gerçekleştirilebilmesi için ilk etapta e-posta yoluyla teknik destek verilerek yaşanan sorunlar giderilmiştir. Oluşturulan grup listeleri sisteme yüklenerek ilan edilmiştir. Ayrıca Duyurular başlığı aktif hale getirilerek 
ders ile ilgili ilk duyurular ve sistemle ilgili yönlendirmeler yapılmaya başlanmıştır. Kontrol grubunda ise ikinci haftaya kadar öğrencilerle yüz yüze veya e-posta yoluyla grup bilgileri paylaşılmıştır.

2. hafta yapılan dersin başlangııında deney grubuna Moodle sisteminde ders kaydı oluşturmalarının ardından neler yapacakları anlatılıştır. Sistemin kullanımı anlatılarak teknik destek istemeleri durumunda gerekli desteğin nasıl verileceği anlatılış̧ır.

2. haftanın da tamamlanmasının ardından 3. hafta itibariyle gruplarda ilk anlatımlar yapılmaya başlanmıştır. Anlatımlar ile ilgili olarak deney grubunda yer alan ilk gruba o haftaya ait bölümü nasıl yönetecekleri ve neleri nasıl paylaşacakları konusunda yönlendirmeler yapılmıştır. Sınıfta yapılan anlatımlar sırasında getirilen uygulamaya yönelik materyallerin ve diğer görsellerin fotoğrafları çekilerek anlatımın hemen ardından sisteme yüklenmeleri sağlanmıştır. Kontrol grubunda ise belirtilen materyalleri ders sonrasında istedikleri şekilde paylaşabilmeleri sağlanmıştır. Anlatımların tamamlanmasının ardından dersi yürüten araştırmacılar ve sınıfta yer alan öğrenciler araştırma sürecini ve anlatım sürecini değerlendirerek gruplara anlık dönütler vermişlerdir. Bu değerlendirmeler doğrultusunda gruplar da kendi araştırma sonuçları yardımıyla belirtilen sorulara cevaplar vermiş ve eksik olan noktalar ile ilgili notlar almışlardır.

Sınıfta gerçekleşen değerlendirmelerin ardından ise deney grubunda yer alan tüm öğrencilerin bir sonraki haftaya kadar sisteme giriş yaparak gruba ait paylaşımlarla ilgili yorumlarını belirtilen forumlarda paylaşmaları istenmiştir. Bu yorumlara göre de anlatım yapan grubun araştırma sonuçlarını ve bilgilerini yeniden düzenlemesi istenmiştir. Bu paylaşımların her grup için dönem sonuna kadar sürekli olarak takip edilerek yapılabileceği belirtilmiştir. Kontrol grubunda ise sınıfta yapılan değerlendirmelerin ardından grupların gerekli düzenlemeleri yapmaları istenmiştir.

Derse ait ara sınav ve dönem sonu sınavlarında, grupların araştırmaları doğrultusunda sunmuş oldukları bilgilerin kullanılacağı, dolayısıyla dönem içerisindeki tüm bu paylaşımların iyi takip edilmesi ve konuların iyi öğrenilmesi gerektiği hem deney hem de kontrol gruplarına belirtilmiştir. Ayrıca deney grubunda yer alanların sistemde aktif olarak yer alıp almadıkları sürekli olarak kontrol edilerek her hafta grupların takip durumların belirten bir tablo ilan edilmiştir. Tüm üyeler bu tablodan hangi haftalar ile ilgili eksiklikleri olduğuna bakarak aktiflik durumlarını kendileri de takip etmişlerdir.

Bu anlatımlar, deney ve kontrol gruplarında her hafta ikişer grup anlatım yapacak şekilde toplamda 10 hafta sürmüştür. 10 haftanın sonunda genel bir değerlendirme yapılarak tüm grupların genel eksiklikleri, dönem içerisindeki durumları ile ilgili görüşme yapılmıştır. Bunların ardından her iki grupta da son testlerin uygulaması yapılmıştır. Ayrıca testlerden elde edilen puanlar da göz önünde bulundurularak deney grubundan 8 öğrenci belirlenmiş ve bu öğrenciler ile yarı yapılandırılmış görüşme yapılmıştır.

\section{BULGULAR ve YORUMLAR}

Araştırmadan elde edilen nicel veriler IBM SPSS 21.0 programı ile analiz edilmiştir. Analizlerde anlamlıık düzeyi .05 olarak alınmıştır. Nitel verilerin analizinde ise betimsel analiz kullanılmıştır. Betimsel analiz, elde edilen verilerin, daha önceden belirlenmiş olan temalar çerçevesinde yorumlanması sürecidir (Yıldırım ve Şimşek, 2013). Betimsel analizde dikkate alınacak olan temalar literatürde yer alan kavramlardan veya veri toplama sürecinde kullanılan sorulardan yola çıkılarak oluşturulabilir. Çalışmada bu temalar yarı yapılandırılmış görüşme sorularının hazırlanması aşamasında soruların içerikleri doğrultusunda oluşturulmuştur. Görüşmeden elde edilen veriler bu temalar çerçevesinde analiz edilmiştir. 


\subsection{Araștırmanın Nicel Verilerine İlişkin Bulgular}

Teknolojiye yönelik tutum ve fen öğretimine yönelik öz-yeterlik inancı ölçeklerine ait ön ve son testlerden elde edilen puanlar analiz edilerek aşağıda yer alan bulgular elde edilmiştir.

Tablo 1, öğretmen adaylarının teknolojiye yönelik tutum ölçeğinden ve fen öğretimine yönelik öz-yeterlik inancı ölçeğinden almış oldukları ön test puanlarının karşılaştırıldığı bağımsız gruplar t-testi bulgularını göstermektedir. Bulgular, deney ve kontrol gruplarının teknolojiye yönelik tutum ön test puanları arasında anlamlı bir farklılık bulunduğunu göstermektedir $(p=.019)$. Buna göre araştırmanın başlangıç aşamasında deney ve kontrol gruplarının teknolojiye yönelik tutumları arasında farklılık bulunmakta olup, deney grubunun ortalamasının daha yüksek olduğu görülmektedir. Fen öğretimine yönelik öz-yeterlik inancı ölçeğine ait bulgular ise deney ve kontrol gruplarının ön test puanları arasında anlamlı bir farklılık bulunmadığını göstermektedir $(p=.236)$. Buna göre deney ve kontrol gruplarının fen öğretimine yönelik öz-yeterlik inançlarının başlangıçta aynı düzeyde olduğu söylenebilir.

Tablo 1

Deney ve Kontrol Gruplarının Ön Test Puanlarının Karşılaştırılması

\begin{tabular}{lllllll}
\hline & & $\mathbf{N}$ & $\mathbf{X}$ & $\mathbf{S s}$ & $\mathbf{F}$ & $\mathbf{p}$ \\
\hline \multirow{2}{*}{ TEKNOLOJiYE YÖNELIK TUTUM } & Karma Öğrenme & 43 & 3.6228 & .33935 & & \\
\cline { 2 - 5 } & Yüz Yüze Eğitim & 45 & 3.4715 & .25193 & .637 & \multirow{2}{*}{.019} \\
\hline \multirow{2}{*}{ ÖZ-YETERLIK INANCI } & Karma Öğrenme & 43 & 3.7984 & .34052 & & \\
\cline { 2 - 5 } & Yüz Yüze Eğitim & 45 & 3.7122 & .33732 & & \multirow{2}{*}{0.236} \\
\hline
\end{tabular}

Tablo 2 ise, öğretmen adaylarının teknolojiye yönelik tutum ölçeğinden ve fen öğretimine yönelik öz-yeterlik inancı ölçeğinden almış oldukları son test puanlarının karşılaştırıldığı bağımsız gruplar t-testi bulgularını göstermektedir. Bulgular, deney ve kontrol gruplarının teknolojiye yönelik tutum son test puanları arasında anlamlı bir farklılık bulunmadığını göstermektedir $(p=.644)$. Buna göre araştırma sonucunda deney ve kontrol gruplarının teknolojiye yönelik tutumları arasında farklılık bulunmadığı görülmektedir. Benzer şekilde fen öğretimine yönelik öz-yeterlik inancı ölçeğine ait bulgular da deney ve kontrol gruplarııın son test puanları arasında anlamlı bir farklılık bulunmadığını göstermektedir $(p=.106)$. Buna göre deney ve kontrol gruplarının fen öğretimine yönelik öz-yeterlik inançlarının araştırma sonunda aynı düzeyde olduğu söylenebilir.

Tablo 2

Deney ve Kontrol Gruplarının Son Test Puanlarının Karşılaştırılması

\begin{tabular}{|c|c|c|c|c|c|c|}
\hline & & $\mathbf{N}$ & $\mathbf{x}$ & Ss & $\mathbf{F}$ & $\mathbf{p}$ \\
\hline \multirow{2}{*}{ TEKNOLOJIYE YÖNELIK TUTUM } & Karma Öğrenme & 43 & 3.5153 & .33187 & \multirow{2}{*}{3.072} & \multirow{2}{*}{.644} \\
\hline & Yüz Yüze Eğitim & 45 & 3.5451 & .27035 & & \\
\hline \multirow{2}{*}{ ÖZ-YETERLIK INANCI } & Karma Öğrenme & 43 & 3.7298 & .41962 & \multirow{2}{*}{.164} & \multirow{2}{*}{.106} \\
\hline & Yüz Yüze Eğitim & 45 & 3.8751 & .41442 & & \\
\hline
\end{tabular}

Öğretmen adaylarının ön test puanlarına bakıldığında teknolojiye yönelik tutum puanları arasında anlamlı bir farkın bulunduğu, yani başlangıçta iki grubun bu değişken 
açısından aynı düzeyde olmadıkları görülmüştür. Buna ek olarak son test puanlarına bakıldığında gruplar arasında anlamlı bir farklılık olmadığı görülmüştür. Bu sebeple çalışmadan elde edilen son test puanlarının ardından grupların erişi puanları (sontest-öntest) hesaplanarak, çalışmanın sonuçlarına dair analizler bu puanlar üzerinden yapılmıştır. Benzer şekilde fen öğretimine yönelik öz-yeterlik inancı puanlarına bakıldığında hem ön hem de son testler arasında anlamlı bir farklılık bulunamadığı için, bu değişkenin incelenmesinde de erişi puanlarının hesaplanması yoluna gidilmiştir.

Tablo 3, öğretmen adaylarının teknolojiye yönelik tutum erişi puan ortalamalarının karşılaştırıldığı t testine ait bulguları göstermektedir. Bulgulara bakıldığında, deney ve kontrol gruplarının teknolojiye yönelik tutum erişi puanları arasında anlamlı bir farklılık görülmektedir $(p=.027)$. Ayrıca söz konusu farklııık kontrol (yüz yüze eğitim) grubu lehine olmuştur. Karma öğrenme grubuna ait puanlarda uygulamalar sonrasında bir düşüş görülürken ( $X=-.0397)$, yüz yüze eğitim grubunda bir artış $(X=.1125)$ söz konusu olmuştur.

Tablo 3

Deney ve Kontrol Gruplarının Teknolojiye Yönelik Tutum Erişi Puanlarının Karşılaştırılması

\begin{tabular}{|c|c|c|c|c|c|c|}
\hline & & $\mathbf{N}$ & $\mathbf{x}$ & Ss & $\mathbf{F}$ & $\mathbf{p}$ \\
\hline \multirow{2}{*}{ TEKNOLOJIYE YÖNELIK TUTUM } & Karma Öğrenme & 43 & -.0397 & 37975 & \multirow{2}{*}{.006} & \multirow{2}{*}{.027} \\
\hline & Yüz Yüze Eğitim & 45 & .1125 & .24220 & & \\
\hline
\end{tabular}

Tablo 4 ise öğretmen adaylarının fen öğretimine yönelik öz-yeterlik inancı erişi puanı ortalamalarının karşılaştıııldığı t testine ait bulguları göstermektedir. Bulgular, deney ve kontrol gruplarının fen öğretimine yönelik öz-yeterlik inancı erişi puanları arasında anlamlı bir farklıığın bulunduğunu işaret etmektedir ( $p=.007)$. Her iki grupta da değişkene ait puanlarda artış gözlemlenirken, kontrol grubunda bu artış daha fazla olmuştur.

Tablo 4

Deney Ve Kontrol Gruplarının Fen Öğretimine Yönelik Öz-Yeterlik Inancı Erişi Puanlarının Karşılaştırılması

\begin{tabular}{|c|c|c|c|c|c|c|}
\hline & & & $\mathrm{x}$ & Ss & $\mathbf{F}$ & $\mathbf{p}$ \\
\hline \multirow{2}{*}{ ÖZ-YETERLIK INANCI } & Karma Öğrenme & 43 & .0563 & 31379 & \multirow{2}{*}{.722} & \multirow{2}{*}{.007} \\
\hline & Yüz Yüze Eğitim & 45 & 2227 & 24672 & & \\
\hline
\end{tabular}

\subsection{Araştırmanın Nitel Verilerine iliş̧kin Bulgular}

Araştırmanın nitel boyutunda, araştırmaya katılan öğretmen adaylarından 8'i ile yarı yapılandırılmış görüşme yapılmıştır. Görüşmeler öğretmen adaylarının izni alınarak ses kayıt cihazı ile kayıt altına alınmış ve görüşme sonrasında yazılı hale getirilmiştir. Elde edilen nitel veriler betimsel analiz yöntemi ile analiz edilmiştir. Bu kapsamda, öğretmen adaylarına sormak üzere hazırlanan açık uçlu sorulardan yola çıkılarak temalar oluşturulmuştur. Öğretmen adaylarının vermiş olduğu cevaplar bu temalar çerçevesinde kategorize edilmiş ve frekans değerleri belirlenerek her bir soru için tablolaştırılmıştır. 


\subsubsection{Teknolojinin öğretim sürecinde kullanımına ilişkin bulgular}

Öğretmen adaylarının "Teknolojinin öğretim sürecinde kullanımı konusunda neler düşünüyorsunuz?" sorusuna vermiş oldukları cevaplar, teknolojinin öğretim sürecinde kullanımının "gerekli" ve "gereksiz" olması şeklinde iki kategori altında incelenmiştir. Bu kategoriler altında ise, öğretmen adaylarının belirtmiş oldukları gerekçeler maddeler halinde yazılarak, cevaplarında söz konusu maddeye yer veren kişi sayıları (frekans) belirtilmiştir. Öğretmen adaylarından 7'si öğretim sürecinde teknoloji kullanımını gerekli bulurken, 1'i gereksiz bulmuştur. Bunun gerekçesini ise fiziksel imkânlar ile açıklamıştır. Tablo 5, bu cevaplara ait dağılımları detaylı şekilde göstermektedir.

Tablo 5

Teknolojinin Öğretim Sürecinde Kullanımına ilişskin Cevaplar

\begin{tabular}{|c|c|c|c|}
\hline Kategori & & Gerekçe & Frekans \\
\hline \multirow{4}{*}{ Gerekli } & \multirow{4}{*}{ Çünkü } & Teknoloji, çağın bir getirisi & 6 \\
\hline & & Bilgiye her zaman ulaşmayı mümkün kılıyor & 2 \\
\hline & & Bilginin hafızada yer etmesi kolaylaşıyor & 2 \\
\hline & & Derslere hazırlanmak daha kolay oluyor & 2 \\
\hline Gereksiz & Çünkü & Her yerde aynı imkânları bulmak zor & 1 \\
\hline
\end{tabular}

Öğretmen adaylarının soruya ilişkin vermiş oldukları cevaplara örnekler:

Ö5: “...teknolojiyle ve getirdiği görsellikle birlikte bilgilerin hafızada yer etmesi daha kolay olmakta..."

Ö7: “...Çocukların görsel hafızaları daha iyi oluyor. Bu sebeple onlara hitap edebilmek için teknolojiyi kullanmak gerektiğini düşünüyorum..."

\subsubsection{Bir öğretmen olarak teknoloji kullanımına ilişkin bulgular}

Öğretmen adaylarının "Bir fen bilgisi öğretmeni olarak derslerinizde teknolojiyi kullanmanız konusunda ne düşünüyorsunuz?" sorusuna vermiş oldukları cevaplar, derslerde teknolojiyi kullanıp kullanmamaları durumlarına göre iki kategoriye ayrılmıştır. Bu kategoriler altında ise bu ifadelerine yönelik gerekçeleri sıralanmıştır. Öğretmen adaylarının 6'sı teknolojiyi kullanacağını belirtirken, 2 öğretmen adayı teknolojiyi kullanmayacağını belirtmiştir. Tablo 6 , bu cevaplara ait dağılımları detaylı şekilde göstermektedir.

Tablo 6

Bir Öğretmen Olarak Teknoloji Kullanımına ilişsin Cevaplar

\begin{tabular}{|c|c|c|c|}
\hline Kategori & & Gerekçe & Frekans \\
\hline \multirow{3}{*}{ Kullanırım } & \multirow{3}{*}{ Çünkü } & Gerekli eğitimleri alarak rahatlıkla kullanabilirim & 5 \\
\hline & & Uygulamak zorundayım & 2 \\
\hline & & Öğrenciler de rahatlıkla kullanabilmekteler & 1 \\
\hline \multirow[t]{2}{*}{ Kullanmam } & Çünkü & Teknoloji kullanımı konusunda yeterli olduğuma inanmıyorum & 2 \\
\hline & & Teknolojiye uyum sağlayamayabilirim & 2 \\
\hline
\end{tabular}


Öğretmen adaylarının soruya ilişkin vermiş oldukları cevaplara örnekler:

Ö1: “...bir korku var içimde acaba yapabilir miyim? diye...ama eğer yeterli düzeyde öğrenirsem uygulayabileceğimi düşünüyorum..."

Ö4: “...faydalanmak zorunda olduğumu düşünüyorum. Gerekli...”

\subsubsection{Fen öğretim sürecinin yönetimine ilişkin bulgular}

"Bir fen bilgisi öğretmeni olarak fen öğretim sürecini yönetebilmeniz konusunda ne düşünüyorsunuz?" sorusuna verilen cevaplar, fen öğretim sürecini "yönetebilirim" ve "yönetemem" şeklinde iki kategori altında incelenmiştir. Bu kategoriler kapsamında öğretmen adaylarının vermiş oldukları gerekçeler de frekans değerleri ile birlikte maddeler halinde sıralanmıştır. Buna göre, öğretmen adaylarının 4'ü öğretim sürecini rahatlıkla yönetebileceğini belirtirken, diğer 4 öğretmen adayı öğretim sürecini rahat yönetemeyeceğini belirtmiştir. Tablo 7, verilen cevapların dağılımını göstermektedir.

Tablo 7

Bir Öğretmen Olarak Fen Öğretim Sürecinin Yönetimine ilişskin Cevaplar

\begin{tabular}{|c|c|c|c|}
\hline Kategori & & Gerekçe & Frekans \\
\hline \multirow{5}{*}{ Yönetebilirim } & \multirow{5}{*}{ Çünkü } & Sınıf hâkimiyetini kurmak kolay & 4 \\
\hline & & Öğretim sürecindeki yeniliklere açığım & 2 \\
\hline & & Teknolojiyi kullanarak süreci kolaylaştırırım & 1 \\
\hline & & Öğrenme ve öğretme hevesim fazla & 1 \\
\hline & & Ben iyi motive olursam öğrenciler de motive olur & 1 \\
\hline \multirow{5}{*}{ Yönetemem } & \multirow{5}{*}{ Çünkü } & Öğrencinin seviyesine indirgemek çok zor & 2 \\
\hline & & Yeterli düzeyde bilgim yok & 2 \\
\hline & & Yeterince kavramamızı sağlayacak bir eğitim almadık & 2 \\
\hline & & Planlamasını yapmak bile çok zor & 1 \\
\hline & & Özgüvenim yok & 1 \\
\hline
\end{tabular}

Öğretmen adaylarının soruya ilişkin vermiş oldukları cevaplara örnekler:

Ö5: “...dersi iyi yönetebileceğimi düşünmüyorum. Çünkü nasıl uygulayacağımı pek öğrendiğimi düşünmüyorum..."

Ö6: “...Kendime güveniyorum yeteri kadar...öğrenme ve öğretme hevesim fazla. Kendim motive olduğum için insanları da motive edebileceğimi düşünüyorum öğrenme konusunda..."

\subsubsection{Kullanılan öğrenme yönetim sisteminin öğretim sürecine katkılarına ilişkin} bulgular

"Kullandığınız öğrenme yönetim sisteminin öğretim sürecine katkıları konusunda neler düşünüyorsunuz?" sorusuna öğretmen adaylarının vermiş oldukları cevaplar "Katkısı var" ve 
"Katkısı yok" şeklinde iki kategori altında incelenmiştir. Öğretmen adaylarının vermiş oldukları cevaplar bu kategorilere göre incelendiğinde, öğretmen adaylarından 6'sı sistemin öğretim sürecine katkısı olduğunu belirtirken, 2'si katkısı bulunmadığını belirtmiştir. Tablo 8, öğretmen adaylarının vermiş oldukları cevapların gerekçelerini ve frekansları içeren dağılımı göstermektedir.

Tablo 8

Öğrenme Yönetim Sisteminin Öğretim Sürecine Katkılarına ilişskin Cevaplar

\begin{tabular}{|c|c|c|c|}
\hline Kategori & & Gerekçe & Frekans \\
\hline \multirow{4}{*}{ Katkısı var } & \multirow{4}{*}{ Çünkü } & Daha akılda kalıcı oluyor & 2 \\
\hline & & Öğrenme açısından iyi bir uygulama & 1 \\
\hline & & Farklı kaynak ve yorumlardan faydalanabiliyoruz & 1 \\
\hline & & Gerekçe belirtmemiş & 2 \\
\hline \multirow{3}{*}{ Katkısı yok } & & Eksik yönleri var & 1 \\
\hline & Çünkü & & \\
\hline & & Sistemin kullanımı zor & 1 \\
\hline
\end{tabular}

Öğretmen adaylarının soruya ilişkin vermiş oldukları cevaplara örnekler:

Ö5: “...Sistemin kötü olduğunu düşünüyorum. Eksikleri var... Öğrenci ve öğretmen katılımının biraz daha fazla olması lazım..."

Ö1: “...Farklı bilgiler, yorumlar ve kaynaklardan yararlandım..."

\section{SONUÇ, TARTIŞMA VE ÖNERILER}

Öğretmen adaylarının fen öğretimine yönelik öz-yeterlik inançlarındaki değişimin incelendiği nicel bulgulara bakıldığında, deney ve kontrol gruplarına ait puanların her ikisinde de artış görülürken, kontrol grubuna ait artışın deney grubuna göre anlamlı derecede yüksek olduğu görülmüştür. Bu noktada karma öğrenmenin fen öğretimine yönelik öz-yeterlik inancı bakımından yüz yüze öğrenmeye kıyasla daha az etkili olduğundan bahsedilebilir. Nitekim, görüşmelerden elde edilen nitel bulgulara bakıldığında da sonuçlar nicel verileri destekler niteliktedir. Bulgularda, bazı öğretmen adaylarının fen öğretimini etkili hale getirebilecek etmenlere ve gelişmelere açık olmalarının ve süreci kolaylıkla idare edebileceklerine inanmalarının yanı sıra önemli bir kısmının da olumsuz düşüncelerinin bulunduğu görülmüştür. $\mathrm{Bu}$ olumsuz düşüncelerin gerekçesi olarak ise yeterli düzeyde bilgilerinin olmamasından, içerikleri öğrenci seviyelerine indirgemenin zorluğundan ve dersin planlanmasının zorluğundan bahsedilmiştir.

Teknolojiye yönelik tutum açısından bakıldığında ise nicel bulgular, karma öğrenme yöntemiyle öğrenim gören (deney grubu) öğretmen adaylarının teknolojiye yönelik tutum puanlarında anlamlı bir düşüş, yüz yüze eğitim ortamının bulunduğu kontrol grubunda ise artış olduğu göstermiştir. Görüşmelerden elde edilen nitel veriler, bu sonuçlara farklı bir bakış açısı getirmektedir. Tutum puanlarında anlamlı bir düşüş gösteren öğretmen adaylarının büyük bölümü teknolojinin gerekli olduğunu, öğretim sürecini kolaylaştırdığını ve bir öğretmen olarak teknolojiyi öğretim sürecinde kullanacaklarını belirtmektedirler. Bu bulgular, literatürde yer alan bulgularla örtüşmektedir (Balcı, 2008; Karaman, Özen, Yıldırım ve Kaban, 2009). Ancak, 
teknolojiyi öğretim sürecinde kullanmayacağını belirten öğretmen adayları, kendilerini bu teknolojiyi kullanma ve idare etme noktasında yetersiz gördüklerini, bu sebeple bu teknolojileri kullanamayacaklarını belirtmişlerdir. Yani öğretmen adayları genel anlamda derslerinde teknolojik materyal ve içerik kullanımı konusunda olumlu tutumlara sahipken, karma öğrenme sürecinde bu tutumlarında literatürün aksine (Aytaç ve Altunçekiç, 2012; Demirer, 2009) olumsuz yönde etkilerin oluştuğu görülmüştür.

Fen derslerinin içeriğinde öğrenilen bilgilerin uygulanması, laboratuvar çalışmaları ve yüz yüze etkileşim oldukça fazladır. Karma öğrenme ortamında bu etkileşimin çevrimiçi ortama aktarılıyor olması, öğretmen adaylarının puanlarındaki bu düşüşlerin bir sebebi olarak görülebilir. Çünkü öğretmen adayları karma öğrenme sürecinde yüz yüze etkileşimin yerine teknolojiyi iyi kullanabilme becerisinin önemli olduğunu ve bu durumun onlarda öğrenmeöğretme süreci ile ilgili kaygılar oluşturduğunu belirtmişlerdir. Bu açıdan bakıldığında karma öğrenme sürecinde yer alan öğretmen adaylarının hem teknolojiye yönelik tutumlarının hem de fen öğretimine yönelik öz-yeterlik inançlarının negatif yönde etkilenmesi olası bir durumdur.

Araştırmadan elde edilen bulgular ışı̆̆ında aşağıdaki öneriler getirilmektedir:

- Teknoloji kullanımı öğretim süreci için oldukça önemli bir bileşen olarak görülse de, yüz yüze uygulamalı etkinliklerin fazlasıyla yer aldığı fen derslerinde öğretimin etkisini azaltabilir. Bu sebeple yapılacak olan çalışmalarda teknolojiye ağırlıklı olarak yüz yüze öğretimin yetersiz kaldığı çeşitli uygulamalarda (tehlikeli laboratuvar uygulamaları, soyut kavramların anlatımı... gibi) yer verilmesi, karma öğrenme sürecinin daha etkili olmasını sağlayabilir.

- Karma öğrenme araştırmalarında ders içeriklerinin sınıf içi ve sınıf dışı bölümlerini planlamadan önce, öğrencilerin var olan öğrenme ortamında ne gibi zorluklar yaşadıklarına dair bir ön araştırma yapılması ve internet üzerindeki içeriklerin bu zorlukları aşmaya yönelik olarak tasarlanması daha etkili bir öğretim sağlayabilir. Bu sayede sunulan teknolojik altyapının daha etkili kullanılması için uygun şartlar sağlanabilir.

- Öz-yeterlik inancı ve tutum gibi değişkenlerin inceleneceği çalışmalarda nitel verilerin olabildiğince artırılması ve verilerin çalışma süresince belirli periyotlarla toplanması, katılımcılarda meydana gelen değişimlerin gerçek nedenlerinin daha iyi tespit edilmesini sağlayabilir.

\section{KAYNAKLAR}

Akbaba, S. (2002). Okul yöneticilerinin teknolojiye karşı tutumlarının incelenmesi. Çağdaş Eğitim Dergisi, 286, 9-14.

Akgündüz, D., Akınoğlu, O. (2016). The effect of blended learning and social media-supported learning on the students' attitude and self-directed learning skills in science education. The Turkish Online Journal of Educational Technology, 15(2), 106-115.

Altıparmak, M., Kurt, i. D., Kapıdere, M. (2011). E-öğrenme ve uzaktan eğitimde açık kaynak kodlu öğrenme yönetim sistemleri. XIII. Akademik Bilişim Konferansı, İnönü Üniversitesi, Malatya.

Aytaç, T. ve Altunçekiç, A. (2012). Karma öğrenme yönteminin başarıya etkisi ve eğitim yöneticilerinin görüşleri. Gazi Üniversitesi Gazi Eğitim Fakültesi Dergisi, 32(3), 867-884.

Balcı, M. (2008). Karma öğrenme ile ilgili öğrenci görüşleri. Yüksek Lisans Tezi, Hacettepe Üniversitesi Fen Bilimleri Enstitüsü, Ankara. 
Barkley, B. W. (2010). The effects of blended online versus face-to-face learning environments on student outcomes for eighth grade algebra I students. Doctoral Thesis, Trevecca Nazarena University.

Barrios, M., Gonzalez-Teruel, A., Cosculluela, A., Fornieles, A., Turbany, J. (2014). Structure and performance assessment in traditional face-to-face and blended learning statistics courses. Procedia-Social and Behavioral Sciences, 141, 1259-1262.

Bıkmaz, F. (2002). Fen öğretiminde öz-yeterlik inancı ölçeği. Eğitim Bilimleri ve Uygulama, 1(2), 197-210.

Caner, M. (2009). A study on blended learning model for teaching practice course in pre-service English language teacher training program. Doktora Tezi, Anadolu Üniversitesi, Eskişehir.

Chang, N. (2006). E-discussions as a complement to traditional instruction: Did the students like online communication and why? Journal of Early Childhood Teacher Education, 27, 249-264.

Chou, A.Y., Chou, D.C. (2011). Course management systems and blended learning: an innovative learning approach. Decision Sciences Journal Of Innovative Education, 9(3), 463-484.

Creswell, J. W. (2013). Araştırma deseni (Çeviri Edt: S. Beşir Demir). Eğiten Kitap: Ankara.

Demirer, V. (2009). Eğitim materyali geliştirilmesinde karma öğrenme yaklaşımının akademik başarı, bilgi transferi, tutum ve öz-yeterlik algısına etkisi. Doktora Tezi, Selçuk Üniversitesi, Konya

Elmas, Ç., Doğan, N., Biroğul, S., Koç, M. S. (2008). Moodle eğitim yönetim sistemi ile örnek bir dersin uzaktan eğitim uygulaması. Bilişim Teknolojileri Dergisi, 1(2), 53-62.

Güler, B. (2013). Karma öğrenme yönteminin ilköğretim fen ve teknoloji öğretmen adaylarının teknolojiye yönelik tutumlarına ve özdüzenleme ve bilimsel süreç becerilerine etkisi. Yüksek Lisans Tezi. Dokuz Eylül Üniversitesi, İzmir.

İşman, A., Abanmy, F. A., Hussein, H. B., Al Saadany, M. A. (2012). Using blended learning in developing student teachers teaching skills. The Turkish Online Journal Of Educational Technology, 11(4), 336-342.

Karaman, S., Özen, Ü., Yıldırım, S., Kaban, A. (2009). Açık kaynak kodlu öğretim yönetim sistemi üzerinden internet destekli (harmanlanmış) öğrenim deneyimi. XI. Akademik Bilişim Konferansı, Şanlıurfa.

Kayalar, F. (2016). Coress-cultural comparison of teachers' views upon integration and use of technology in classroom. The Turkish Online Journal of Educational Technology, 15(2), 11-19.

Lim, D. H., Morris, M. L., Kupritz, V. W. (2007). Online vs. blended learning: differences in instructional outcomes and learner satisfaction. Journal of Asynchronous Learning Networks, 11(2), 27-42.

Panga, G. C. (2010). A study of adult students' perceptions of the traditional distance education programs and the option of a blended learning model in sub-saharan africa. Doctoral Thesis, Capella University. 
Relan, A. ve Gillani B. B. (1997). Web-based Instruction and the traditional classroom: similarities and differences. Web-based Instruction, 25-37. New Jersey: Educational Technology Publications

Riggs, I. M. ve Enochs, L. G. (1990). Toward the development of an elementary teacher's science teaching efficacy belief instrument. Science Education, 74(6), 625-637.

Rovai, A. P., Jordan, H. M. (2004). Blended learning and sense of community: a comparative analysis with traditional and fully online graduate courses. International Review of Research in Open and Distance Learning, 5(2).

Sinecen, M. (2010). Uzaktan eğitimde moodle kullanımı ve kurulumu. Akademik Dizayn Dergisi, 1, 14-21.

Turney, C. S. M., Robinson, D., Lee, M., Soutar, A. (2009). Using technology to direct learning in higher education: the way forward? Active Learning in Higher Education, 10, 71.

Usta, E., Mahiroğlu, A. (2008). Harmanlanmış öğrenme ve çevrimiçi öğrenme ortamlarının akademik başarı ve doyuma etkisi. Ahi Evran Üniversitesi Kırşehir Eğitim Fakültesi Dergisi, 9(2), 1-15.

Uzun, A., Şentürk, A. (2010). Blending makes the difference: comparison of blended and traditional instruction on students' performance and attitudes in computer literacy. Contemporary Educational Technology, 1(3), 196-207.

Ünsal, H. (2007). Harmanlanmışöğrenme etkinliğinin çoklu düzeyde değerlendirilmesi. Doktora Tezi, Gazi Üniversitesi Eğitim Bilimleri Enstitüsü, Ankara.

Yıldırım, A., Şimşek, H. (2013). Sosyal Bilimlerde Nitel Araştırma Yöntemleri. Ankara: Seçkin Yayınları. 


\section{SUMMARY}

Science education aims to train conscious individuals who are able to improve the quality of their life by solving the problems they encountered. For this reason, all elements of daily life take place in science education. It brings the need for new elements that may facilitate the teaching process. Technology, whose place in daily life is unchallenged, is one of those elements. It is used in most of learning environments for both making individuals ready for life conditions and making the teaching process easy.

One of the new methods to provide more accessible learning environments to individuals is "Blended Learning". Blended learning is a process that Internet-aided teaching and traditional face to face teaching are used together. It means, teaching is sustained using activities both in and out of the classroom. Although technology is included in both of these environments, out of class activities use technology to provide same communication and collaboration conditions as classroom activities. Therefore, it may be possible to learn and sustain this learning in and out of the classroom.

Offering course content in both learning environment, most of them are given in online environment, blended learning allows students to learn and share their experiences in both environment. Thus, the chronological order for learning disappears. It means students can reach all information wherever they want and they can improve themselves whenever they want. This flexibility makes students have positive changes on attitudes towards science learning and develops their selfdirected learning skills (Akgündüz \& Akınoğlu, 2016).

In blended learning, like in all teaching methods, teacher has a crucial role. Blended learning expects teachers to control the process for an effective teaching. In science teaching, use of this method brings more responsibilities to teachers because of the diversity of content. Teacher's attitude and efficacy about this method influence students' learning process (Barrios et al., 2014). Because teachers' self-efficacy and attitudes towards technology effect both their technology usage choices in classroom and effectiveness of their technology-enriched teaching process (Kayalar, 2016). Therefore, teachers need to see and experience the effects of blended learning as learners. These experiences will shape how effective teachers' teaching process will be.

In this context, the aim of this study is to investigate the effects of blended learning method on preservice science teachers' self-efficacy beliefs towards science teaching and attitudes towards technology.

The study was a quasi-experimental study with pre-test post-test and control group. "Selfefficacy Beliefs Instrument in Science Teaching" and "Scale for Attitudes Towards Technology" were used as quantitative data collection tools. These scales were applied as pre and post tests. The Cronbach Alpha values were .64 for "Scale for Attitudes Towards Technology" and .79 for "Self-efficacy Beliefs Instrument in Science Teaching". In the qualitative part, semi-structured interview was chosen. The interview form was examined by 4 science education experts and revised before the interviews.

The quantitative data were analyzed using IBM SPSS 21.0. The level for significance was set as .05. To analyze the qualitative data, descriptive analysis technique was used.

According to findings, although participants' self-efficacy belief scores increased, control group's score was significantly higher than that of the experimental group. The qualitative data from the interviews showed teacher candidates' negative beliefs about effective teaching as the reason of this difference. Teacher candidates explained these negative beliefs with the reasons; not to have sufficient knowledge, difficulties to planning the teaching process and setting the appropriate teaching level for students. The first part was derived from teacher candidates' undergraduate education. They indicated that their undergraduate education was insufficient for applying this kind of science teaching. The second part is the problems with learning management system that was used in this study. They stated that using Moodle system in teaching environment was not easy because of the difficulties of planning the course, organizing the content and balancing the level of teaching. 
On the other hand, experimental group's scores for attitudes towards technology decreased while the control group's score increased. The qualitative expressions showed the Moodle Learning Management System as the reason of this finding. Participants stated that they had some problems such as the complexity of the system and having problems with organizing the content of courses. So they pointed out that they would not use this system in their courses because of its difficulty of use and control.

In addition to the quantitative findings, qualitative findings also supported the results. But the crucial part of the qualitative findings was that teacher candidates pointed out the learning management system (Moodle) as responsible for these low scores. Although they were aware of the contributions of blended learning, they mentioned that Moodle system is hard to use in both learning and teaching. They showed the complex design of system interface as the problem of learning process and the difficulty of planning the course as the problem of teaching process.

The qualitative data gave important details about participants' quantitative results on selfefficacy beliefs towards science teaching. Although some teacher candidates specified that they were open to new developments for a more effective science teaching, nearly half of them were negative about this. That finding supported the quantitative results. Additionally, teacher candidates underlined some factors that might have effected their ideas about self-efficacy. While some of them were derived from their inadequate undergraduate education, some participants pointed out the learning management system as a reason. They showed the undergraduate education as responsible for their insufficiency to teach science in a technology-aided environment like blended learning. Also they found the Moodle system complex and hard to use. This may have affected teacher candidates' self-efficacy negatively.

On the other hand, participants gave similar details about their attitudes towards technology. Although the experimental group's attitude scores decreased from pre to post test, qualitative findings showed that most of the experimental group participants defined technology usage in teaching process as crucial and necessary. The candidates who were reluctant to technology usage stated that they were insufficient to use learning management system. The learning management system was pointed out as the reason of this negative effect.

In brief, the experimental group had lower scores than the expected in both self-efficacy beliefs and attitudes towards technology. The main two reasons were participants' insufficiency and the difficulties about use of Moodle. Teacher candidates' expressions show that the content and the methods used in undergraduate education may affect their self-efficacy and attitudes towards technology. Although they had lower scores, blended learning process might have done a positive effect on participants providing an awareness of their qualification. Furthermore, the problems about learning management system might be derived from participants' abilities to use this technology. From this perspective, involving with similar technologies during undergraduate education may be needed to exceed this difficulty. 